\title{
BEHAVIORAL ECOLOGY OF MORPHOLOGICALLY COMPLEX MARINE ICHNOGENERA
}

\author{
MILLER, William, III, Geology Department, Humboldt State University, Arcata, CA \\ 95521, U.S.A.
}

Certain well known, structurally intricate trace fossils pose special problems for behavioral interpretation. This situation is illustrated by the current controversy over function and ethologic implications of the large, spiralled spreite burrows known collectively as Zoophycos. Rather than being a debate about modal or ideal function, it may indicate failure of traditional ethologic categorization to adequately characterize such complex burrow systems as Zoophycos, certain forms of Chondrites, Ophiomorpha-Thalassinoides, and the more elaborate versions of the enigmatic "graphoglyptids" (e.g., Paleodictyon having many vertical shafts). Based on re-evaluation of these ichnogenera, there appears to be a fundamental difference between incidental biogenic structures, representing a single function or dominant environment-organism interaction, and elaborate animal artefacts representing deliberate control or restructuring of habitats.

Phymatoderma is another example of a morphologically complex ichnogenus that is difficult to categorize using the traditional Seilacherian scheme. Like Zoophycos, it has been interpreted as an elaborate fodinichnion, but on re-examination has yielded some surprises. Some of the most spectacular examples of Phymatoderma occur in Pliocene slope deposits of northwestern Ecuador. Here the mostly horizontal burrow systems consist of bundles of outwardly branching, somewhat overlapping tunnels that originate in a central area and are stuffed with pelleted volcanic ash. As with Kotake's Zoophycos from the Pliocene of Japan, and modern Zoophycos described by Fu and Werner from the Atlantic seafloor, Ecuadorian Phymatoderma represent complex behavior that may have included surface detritus feeding, caching, some form of subsurface deposit feeding, and possibly waste stowage or farming. In general, such structures seem to indicate alternation of feeding-related behavior by trace producers that experienced repeated episodes of local disturbance and resource flux.

Structures like Zoophycos, Ophiomorpha, Paleodictyon and Phymatoderma probably represent complex behavior involving modification of habitat structure, insulation from or damping of the effects of disturbances, active control of trophic resources, and possibly intraspecific communication. If this is so, trying to jam the structures into a traditional ethologic category is bound to fail. These burrow systems may be more akin to multi-functional buildings produced by humans than to structures created by a single or dominant activity or interaction. Employing the concepts of modern behavioral ecology (Hansell's animal artefacts; ecosystem engineering of Jones, Lawton and Shachak; Dawkins' extended phenotype), together with fabrication analysis (analysis of construction, maintenance and operation programs), would advance the study of structurally intricate, ethologically complex ichnogenera beyond the debate over Seilacherian categorization. 